2017-01-05

\title{
Relational Aggression and Marital Quality: A Five-Year Longitudinal Study
}

\author{
Sarah M. Coyne
}

Brigham Young University - Provo, smcoyne@byu.edu

David A. Nelson

Brigham Young University - Provo

Jason S. Carroll

Brigham Young University - Provo

Nathan J. Smith

Brigham Young University - Provo

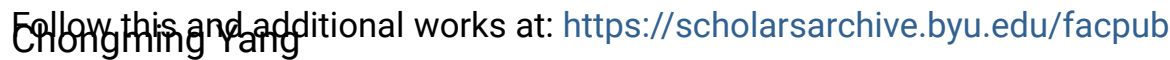

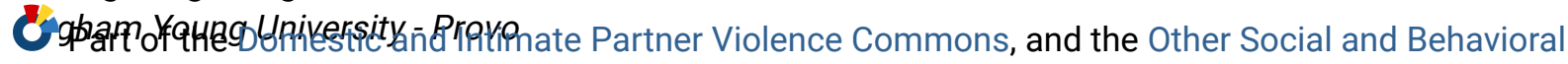

\section{Sciences Commons}

See next page for additional authors

\section{Original Publication Citation}

Coyne, S. M., Nelson, D. A., Carroll, J.S., *Smith, N. J., Yang, C., *Holmgren, H. G., \& *Johnson, C. (2017). Relational aggression and marital quality: A five year longitudinal study. Journal of Family Psychology, 31, 282-293.

\section{BYU ScholarsArchive Citation}

Coyne, Sarah M.; Nelson, David A.; Carroll, Jason S.; Smith, Nathan J.; Yang, Chongming; Holmgren, Hailey G.; and Johnson, Chad, "Relational Aggression and Marital Quality: A Five-Year Longitudinal Study" (2017). Faculty Publications. 4019.

https://scholarsarchive.byu.edu/facpub/4019

This Peer-Reviewed Article is brought to you for free and open access by BYU ScholarsArchive. It has been accepted for inclusion in Faculty Publications by an authorized administrator of BYU ScholarsArchive. For more information, please contact ellen_amatangelo@byu.edu. 


\section{Authors}

Sarah M. Coyne, David A. Nelson, Jason S. Carroll, Nathan J. Smith, Chongming Yang, Hailey G. Holmgren, and Chad Johnson 


\title{
Relational Aggression and Marital Quality: A Five-Year Longitudinal Study
}

\author{
Sarah M. Coyne, David A. Nelson, Jason S. Carroll, Nathan J. Smith, Chongming Yang, \\ Hailey G. Holmgren, and Chad Johnson \\ Brigham Young University
}

\begin{abstract}
Relational aggression occurs in many different contexts, including in romantic relationships. The current study examined associations between two subtypes of relational aggression (love withdrawal and social sabotage) and marital quality over a 5-year time period. Participants consisted of 311 married couples who completed a number of questionnaires on relational aggression and relationship quality once a year over a 5-year period. Results revealed that relational aggression was highly stable over time and that women used more relational aggression than men. Men's use of social sabotage and love withdrawal were bidirectionally related to both partners' perceptions of poor marital quality over time. Conversely, only women's use of love withdrawal was related to her own perceptions of poor marital quality over time. Collectively, these results suggest that relational aggression by men may be less common, though particularly toxic in a marital relationship. Couples are encouraged to find healthier ways of coping with problems in relationships.
\end{abstract}

Keywords: romantic relational aggression, couples, indirect aggression, social aggression, relationship quality

Supplemental materials: http://dx.doi.org/10.1037/fam0000274.supp

A substantial amount of research examines the many manifestations of aggression in romantic relationships. Much of prior research focuses on physical expressions of aggression. Another notable construct is that of psychological aggression. Psychological aggression unfortunately lacks a consistent working definition and conceptualization (Follingstad, 2009), meaning that prior studies may encompass diverse elements such as verbal aggression, love withdrawal, triangulation, financial overcontrol, seclusion, rigid sex role expectations, and perhaps a dozen other strategies (e.g., Graham-Kevan \& Archer, 2009). Moreover, studies have not usually provided enough observed items of each element of psychological control to thoroughly investigate whether a multifactorial view of psychological aggression is more appropriate than merging all items together into one overarching construct (Carroll et al., 2010).

This article was published Online First January 5, 2017.

Sarah M. Coyne, David A. Nelson, Jason S. Carroll, Nathan J. Smith, Chongming Yang, Hailey G. Holmgren, and Chad Johnson, School of Family Life, Brigham Young University.

We thank the Family Studies Center at Brigham Young University (BYU), the School of Family Life, and the College of Family, Home, and Social Sciences at BYU, and recognize the generous support of the many private donors who provided assistance for this project. We also thank those families who were willing to spend valuable hours with our team in interviews and the many students who assisted in conducting the interviews. Portions of this article were presented at the International Society for Research on Aggression conference in 2014.

Correspondence concerning this article should be addressed to Sarah M. Coyne, School of Family Life, Brigham Young University, JFSB 2087, Provo, UT 84602. E-mail: smcoyne@byu.edu
More recently, there is attention to direct and indirect forms of relational aggression in romantic relationships (Carroll et al., 2010; Linder, Crick, \& Collins, 2002). Relationally aggressive strategies may be considered subtypes of psychological aggression, as prior studies tend to include a few items that parallel the strategies we discuss here. Relational aggression is generally defined as a behavior intended to damage a relationship or hurt someone through manipulation or social exclusion (Crick \& Grotpeter, 1995). Such strategies take root beginning in early childhood (Crick \& Grotpeter, 1995), long before romantic relationships are in focus. Direct forms of relational aggression are those in which the aggression transpires face to face. Indirect forms, in contrast, are initiated behind the scenes, with third parties, such as in the case of gossip or rumors. In romantic relationships, relational aggression is uniquely enacted via a range of strategies that vary in severity (Linder et al., 2002). Early studies included withholding physical affection, threatening to end the relationship, flirting with others in front of one's romantic partner to increase feelings of jealousy, or outright infidelity as common strategies (e.g., Linder et al., 2002). Romantic relational aggression is common in romantic relationships of young adults (e.g., Stappenbeck \& Fromme, 2014) as well as married couples (Carroll et al., 2010).

Notably, Carroll et al. (2010) have examined the prevalence and outcomes of relational aggression in marriage by focusing on two subtypes: love withdrawal and social sabotage. This study showed that these constructs may be empirically distinguished and should therefore be separately considered in their mean levels and potential consequences (consistent with a multifactorial view of psychological aggression). Love withdrawal is a direct (face to face) form of romantic relational aggression wherein a spouse withdraws affection and support in the midst of conflict (e.g., silent treat- 
ment). Social sabotage, in contrast, is an indirect form of aggression where partners may spread rumors or gossip about their spouse, or persuade outsiders to take sides in the couples' personal conflicts. Instead of keeping disagreements within the relationship, the perpetrating partner publicly defames or embarrasses their spouse by sharing private information with a third party.

Carroll et al. (2010) found that both subtypes were very common in marriage, with $96 \%$ of wives and $88 \%$ of husbands engaging in some form of relational aggression. Love withdrawal was more frequently cited than social sabotage; however, both subtypes were associated with poor relationship outcomes, including lower levels of marital quality and greater marital instability for both partners. Prior studies indicate that romantic relational aggression is concurrently associated with psychosocial maladjustment, lower relationship quality, frustration, jealousy, clinginess, and less trust in one's partner (Linder et al., 2002). Yet the longitudinal impact of relational aggression in a romantic relationship is not well established. Rather than relational aggression undermining relationship quality, it is possible that spouses are reacting to a preexisting low-quality relationship by lashing out at one another.

Nonetheless, we expect that the interplay between relational aggression and relationship quality will parallel what we tend to see in other longitudinal work regarding marital conflict. For example, research suggests a long-term cumulative effect of physical aggression, negative communication, and general levels of conflict on relationship satisfaction in romantic relationships (Rhoades, Stanley, \& Markman, 2012). Higher levels of psychological aggression are also associated with lower subsequent levels of victim marital satisfaction (Panuzio \& DiLillo, 2010). Accordingly, it is likely that romantic relational aggression may have similar impact over time. It is this long-term relationship that we seek to examine in the current study.

\section{Theoretical Background: Gender and Couple Conflict}

Although marriage researchers use different terminology, they often categorize conflict behaviors between spouses as fitting into one of three types of behaviors: (a) negative or destructive behaviors, (b) positive or constructive behaviors, and (c) withdrawal or disengaged behaviors (Birditt et al., 2010). Negative or destructive behaviors include hostile interactions during couple conflict, such as criticism, contempt, belligerence, and flooding with emotions during arguments (Gottman, 1994). Positive or constructive behaviors consist of helpful interactions such as empathetic listening, clear-sending communication, accepting influence from one's partner, and soothing or staying calm during conflict. Withdrawal or disengaging behaviors involve disconnecting during conflict by not disclosing or engaging in the conversation, or by withdrawing from the disagreement altogether. While these three categories are not specific to any one theory, they do integrate common understandings of conflict patterns in marriage from behavioral or interaction theories.

Theories of couple conflict behavior have also emphasized how conflict behaviors vary between husbands and wives. One of the main tenets of this perspective is that both the frequency and consequences of conflict behaviors for relationship quality may vary depending on whether the husband or wife uses the behavior (Orbuch et al., 2002). For example, studies have identified the "demand-withdrawal" conflict pattern between spouses, wherein wives typically express more demands and husbands exhibit more withdrawal during conflict interactions (e.g., Heavey, Layne, \& Christensen, 1993; Vogel \& Karney, 2002). Vogel and colleagues (2007) explained, "Demanding occurs when one partner pursues changes in the relationship, whereas withdrawal occurs when one partner attempts to avoid discussing a problematic issue in the relationship" (p. 165). Demand and withdrawal behaviors have been suggested to be common in couple relationships, even among relatively satisfied couples (Vogel \& Karney, 2002). Yet these behaviors are of particular concern because they are associated with declines in relationship satisfaction over time (Heavey, Christensen, \& Malamuth, 1995).

One explanation for these gender differences in conflict behaviors is that of power differences between spouses. Power has been defined as "the ability (potential or actual) of an individual to change the behavior of other members in a social system" (Cromwell \& Olson, 1975, p. 5). In relation to couples, power is a concept described often in feminist sociological theory and family therapy as offering key understanding for how differences between partners impact how couples interact and how relationship decisions are made (Knudson-Martin, 2013; Oka, Brown, \& Miller, 2016). Power differences between spouses are particularly related to desire for change in the relationship. Multiple studies (e.g., Eldridge \& Christensen, 2002; Eldridge, Sevier, Jones, Atkins, \& Christensen, 2007; Heavey et al., 1993) have conceptualized desire for change as a "situation-specific" construct that is defined by the degree to which one spouse is dependent on the other for change on a specific aspect of the relationship. Holley and colleagues (2010) explain that

\begin{abstract}
the person who desires change on a given topic is in a low-power position and, therefore, must rely on the partner's compliance and engage in behaviors to elicit change (e.g., by demanding) while conversely, the other partner is in a high-power position, able to preserve the status quo unilaterally by withdrawing from discussions about that topic. (p. 668)
\end{abstract}

It is theorized that because women have been found to typically want more change in relationships than men (e.g., Kluwer, Heesink, \& Van De Vliert, 2000), women most often occupy the demanding position, whereas men occupy the withdrawing position in conflict interaction.

The focus of the present study is a bit different when it comes to the definition of withdrawal tactics in marital interaction. Whereas the demand-withdrawal conflict pattern may focus on pursuit of change in marital dynamics, withdrawal strategies may otherwise be used to (a) simply communicate petulance or contempt (an aggressive overture) or (b) proactively attempt to shift power dynamics so that the affected spouse will potentially feel motivated to make amends and comply with demands of the withdrawing spouse. Regarding the latter possibility, withdrawal is therefore not always a response to deflect a partner's demands for change, but a manipulative demand in and of itself. Moreover, it may be an attempt to induce pursuit by one's spouse, rather than to deflect. This may be particularly important when one spouse feels angered or hurt, and desires to prompt the other to engage in repair efforts.

This is where the concept of marital relational aggression lends additional insight. Prior research (Carroll et al., 2010) shows that both love withdrawal and social sabotage strategies appear to be 
more commonly practiced by wives than husbands. If husbands appear to hold the upper hand in demand-withdraw dynamics, wives may understandably take the lead in regard to love withdrawal. First, wives may seek to shift power dynamics by depriving the spouse of desired emotional and physical expressions of love. Second, this may be a natural extension of the social exclusion tactics that are common to female relationships, going all the way back to preschool (Nelson, Robinson, \& Hart, 2005). In short, wives may more naturally take to marital relational aggression as they have become well practiced over the course of developmental time.

This latter point may be one of the primary reasons why wives may engage in the risky proposition of social sabotage. Whereas love withdrawal keeps the tension within the marital relationship, social sabotage invites outsiders into the couple's problems. Such behavior has the potential to inflict lasting damage in the relationship, as the defamation of the spouse may endure over time. It is likely that the spouse will consider it a form of betrayal. Yet prior experience with relational aggression, common to women's relationships, may make it easier to slip into such negative behaviors and perhaps underestimate the damage that can be inflicted. Consistent with this idea, Nelson, Springer, Nelson, and Bean (2008) found that young adult women are perceived to embrace relational aggression more so than men, especially in cross-gender relationships. Rose (2002) has also shown that females are likely, from an early age, to extensively discuss their problems with friends, and this tendency may drift into married life and promote the unwitting use of social sabotage.

Although relational aggression may be more common in the behavior of wives, a husband's use of relational aggression may be more damaging to marital relationship quality. This may particularly be the case if he is already viewed as having more power in the relationship. More generally, women may best understand the negative impact of relational aggression, given its prominence in prior peer interactions, and the greater emphasis that females tend to place on establishing and maintaining close relationships. The key to understanding these relationships may be social context. Prior peer interactions (peer acquaintances, friends, and transitory dating partners) rarely focus on the permanence or endurance of the given relationship. Permanence, however, is traditionally associated with marriage and requires adjustments to new expectations for behavior. These adjustments may come slowly for many women. They may struggle to modify existing habits which, even if they ended relationships, did not have the same dynamic impact that the end of marriage can have. Social cognition studies regularly show that girls, from an early age, find relational provocations to be more emotionally distressing than boys do (Nelson \& Coyne, 2009), yet girls, when they choose aggressive behaviors, predominantly focus on relationally aggressive strategies. This paradoxical approach to relationships is likely to endure into adulthood (Nelson et al., 2008), but will take on different meaning in the marital context.

\section{Study Aims}

To our knowledge, all research on relational aggression in romantic relationships is cross-sectional. Though the extant literature suggests that relational aggression is common and may be associated with poor relationship quality, these cross-sectional studies do not speak to the direction of effects or if one is associated with changing levels of the other over the course of time. In short, it is important to consider the dynamic interaction that may exist between marital quality and forms of marital relational aggression over time. This presumption is based on the idea that marital quality and relational aggression exist in parallel and may inform one another. There are a number of possibilities to consider in this regard. First, it may be that relational aggression in relationships may simply be a reflection of a long history of dissatisfaction with the relationship. According to this view, aggression may be an artifact of a relationship already in trouble. As relationship quality decreases, inhibitions against inappropriate behavior may gradually fade as contempt for the spouse increases. Anger and frustration give way to aggressive tendencies. Conversely, the practice of relational aggression may directly influence feelings of relationship satisfaction, and this may have a compounding effect over time. In this vein, a long history of love withdrawal and social sabotage may contribute to poor relationship outcomes over time as trust is diminished and victimization breeds resentment. Of course, the two variables may dynamically interact over the course of time, with aggression increasing as marital quality decreases. It is these long-term relationships between relational aggression and marital quality that we examine in the current study. We also examined the relationship between relational aggression and relationship satisfaction in both men and women. As suggested by couple power dynamics theory (Knudson-Martin, 1997, 2013), we predicted that associations may be stronger for husbands' use of relational aggression over time than for wives' use of aggression.

We have decided to examine these relationships over a 5-year time period, instead of over a single year for a number of reasons. First, though marital quality is usually fairly stable over time, couples tend to experience peaks and valleys in their relationship. By examining a 5-year period of time, we hope to get a wider view of relational aggression in marriage as a whole; decreasing the likelihood of assessing couples in a particularly negative year. We also hoped to capture parents during two distinct parenting timeswhen their child was in early adolescence and then middle adolescence. Marital quality can often be influenced by parenting stage (e.g., Gallagher, Huth-Bocks, \& Schmitt, 2015; Lewin, Mitchell, \& Ronzio, 2013) and we hoped to measure these relationships with a more holistic view.

\section{Method}

\section{Participants}

Participants included 311 married couples who were taken from the Flourishing Families Project (FFP), which is an ongoing, longitudinal study of inner family life. Participants were selected from a large northwestern city in the United States and were interviewed once a year for 5 years. Families were primarily recruited using Polk Directories/InfoUSA that describes the presence and age of children in each household. Families identified using this directory were randomly selected from targeted census tracts that mirrored the socioeconomic and racial stratification of reports of local school districts. All families with a child between the ages of 10 and 14 living within target census tracts were deemed eligible to participate in the FFP. Of the 692 eligible 
families contacted, 423 agreed to participate (61\% response rate). Families of lower socioeconomic status were slightly underrepresented by using this technique. Therefore, in an attempt to more closely mirror the demographics of the local area, a limited number of families were recruited into the study through other means (e.g., referrals, fliers; $n=77,15 \%$, for a total $N=500$ ). Only married couples who had complete data over the 5 years were included in the current analysis $(n=311)$.

Once eligibility and consent were established, interviewers made an appointment to come to the family's home to conduct an assessment interview that included videotaped interactions, as well as questionnaires that were completed in the home. It is important to note that there were very few missing data. All questionnaires were screened for missing answers and double marking. The final sample for the current study consists of parents only that were drawn from the FFP study's first five waves of assessment (total $n=500$ families, comprising 337 two-parent families and 163 single-parent families at Wave 1). Only couples that were married and had complete data were included in the current study. Thirteen couples reported cohabiting at Wave 1 and these were excluded from the analysis. Over the course of 5 years, nine couples divorced, three separated, and two were widowed. Data were not included for these families as they did not have partner data at all time points. At Wave 5, the sample consisted of 311 families (92.6\% retention from Wave 1) with a child within the target range. The average age of husbands in the sample was 46.15 years $(S D=6.29)$ at Wave 1 , and the average age of wives was 43.75 years $(S D=6.11)$ at Wave 1 . At Wave 1 , the average length of time in the current relationship was 17.59 years $(S D=5.81)$. Additionally, $75 \%$ of families were of European American ethnicity, $4.2 \%$ were African American, with smaller number for Hispanics $(0.3 \%)$ and Asian Americans (1.2\%). Nineteen percent of families are considered multiethnic in nature, based on a combination of two or more ethnic cultures among family members. In terms of parental education, $72 \%$ of women and $69 \%$ of men had a bachelor's degree or higher. For income, 14\% made less than $\$ 25,000$ per year, $16 \%$ made between $\$ 25,000$ and $\$ 50,000$ a year, and $70 \%$ made more than $\$ 50,000$ per year, with $21 \%$ of twoparent mothers and 5\% of two-parent fathers reporting being unemployed.

\section{Measures}

Romantic relational aggression. Romantic relational aggression was measured using an adapted version (some items simplified) of the Couple Relational Aggression and Victimization Scale (CRAViS; Nelson \& Carroll, 2006). Based on the original SelfReport of Aggression and Victimization (Linder et al., 2002; Morales \& Crick, 1998), the CRAViS was modified in language for committed couples where respondents were instructed to respond about their current relationship. There were two subscales that we will examine in the current study (see the online supplemental material for a complete list of included items). The Love Withdrawal subscale includes six items measuring the degree to which partners feel their spouse withdraws affection and support when there is conflict. Both scales are measured on a 7-point Likert scale ranging from 1 (not at all true) to 7 (very true). Higher scores indicate higher perceived relational victimization.
The Social Sabotage subscale includes six items measuring the degree to which partners feel that their spouse utilizes socially aggressive behaviors in times of conflict and difference. Both scales achieved acceptable reliability at all five waves, with Cronbach's alphas ranging from .86 to .90 for husbands' love withdrawal and from .86 to .88 for wives' love withdrawal, and from .84 to .90 for husbands' social sabotage and from .87 to .90 for wives' social sabotage. Both the Love Withdrawal and Social Sabotage scales are a measure of one spouse's perception of the other's aggression. In order to maintain readability, we refer to the spouses' ratings as actual relational aggression. For example, rather than say "husbands' ratings of wives' relational aggression" throughout the article, we simply say "wives' relational aggression."

Marital quality. Marital quality was assessed using a 5-item modified version of the Quality Marriage Index (Norton, 1983). The responses were based on a 6-point Likert scale ranging from 1 (very strongly disagree) to 6 (very strongly agree). Items included "My relationship with my partner makes me happy" and "My relationship with my partner is very stable." Higher scores indicate higher perceived marital quality. Marital quality achieved acceptable reliability at all five waves, with Cronbach's alphas between .89 and .95 for husbands, and between .92 and .95 for wives.

Control variables. The study also utilized a number of control variables that have been found to relate to either marital quality or aggression in romantic relationships. Education was assessed by asking respondents to report on their highest completed grade/level in school on a 7-point Likert scale, with response options ranging from 1 (less than high school) to 7 (advanced degree). Ethnicity, gender, age, and length of the marital relationship were also controlled.

\section{Results}

\section{Preliminary Analyses}

Means and standard deviations for all main variables can be found in Table 1. We tested for mean differences between husbands and wives on each of the latent constructs across time. Overall, wives reported lower marital quality than did husbands, but only at Waves $2(p<.01)$ and $4(p<.01)$. Husbands also showed lower levels of love withdrawal and social sabotage compared to wives at each wave (all comparisons are $p<.05$ ). For reference, we also tested correlations between all study variables. For readability, only Wave 1 and Wave 2 variables are shown in Table 2.

\section{Cross-Lagged Modeling to Examine Directions of Associations}

The directions of the relationship among love withdrawal, sabotage, and relationship quality were examined with a cross-lagged model, which allowed us to examine the directions of the associations in a dynamic changing system. These latent constructs were measured with the average of two items as indicators, referred to as parceling (Yang, Nay, \& Hoyle, 2009). The two items are randomly selected for the parceling. Consequently, the number of 
Table 1

Means and Standard Deviations of Husbands' and Wives' Marital Quality, Love Withdrawal, and Social Sabotage

\begin{tabular}{|c|c|c|c|c|c|c|}
\hline \multirow[b]{2}{*}{ Variable } & \multicolumn{2}{|c|}{ Husbands } & \multicolumn{2}{|c|}{ Wives } & \multirow[b]{2}{*}{ Difference } & \multirow[b]{2}{*}{ Effect size $(d)$} \\
\hline & $M$ & $S D$ & $M$ & $S D$ & & \\
\hline \multicolumn{7}{|l|}{ Marital quality } \\
\hline Wave 1 & 5.60 & 0.98 & 5.58 & 1.02 & .01 & .02 \\
\hline Wave 2 & 5.36 & 1.06 & 5.23 & 1.18 & $.13^{* * *}$ & .12 \\
\hline Wave 3 & 5.39 & 1.06 & 5.35 & 1.15 & .04 & .04 \\
\hline Wave 4 & 5.35 & 1.06 & 5.22 & 1.16 & $.12^{* * *}$ & .12 \\
\hline Wave 5 & 4.69 & 0.97 & 4.65 & 1.05 & .04 & .04 \\
\hline \multicolumn{7}{|c|}{ Love withdrawal } \\
\hline Wave 1 & 2.47 & 1.26 & 2.90 & 1.26 & $.43^{\text {****** }}$ & .34 \\
\hline Wave 2 & 2.49 & 1.29 & 2.81 & 1.22 & $.32^{\text {****** }}$ & .25 \\
\hline Wave 3 & 2.35 & 1.25 & 2.66 & 1.20 & $.31^{* * * * *}$ & .25 \\
\hline Wave 4 & 2.40 & 1.29 & 2.73 & 1.24 & $.33^{\text {***** }}$ & .26 \\
\hline Wave 5 & 2.38 & 1.32 & 2.73 & 1.23 & $.35^{\text {***** }}$ & .27 \\
\hline \multicolumn{7}{|c|}{ Social sabotage } \\
\hline Wave 1 & 1.40 & 0.77 & 1.58 & 0.94 & $.18^{\text {****** }}$ & .21 \\
\hline Wave 2 & 1.44 & 0.81 & 1.53 & 0.88 & $.09^{*}$ & .11 \\
\hline Wave 3 & 1.34 & 0.66 & 1.54 & 0.92 & $.20^{* * *}$ & .25 \\
\hline Wave 4 & 1.38 & 0.73 & 1.54 & 0.86 & $.16^{* * *}$ & .20 \\
\hline Wave 5 & 1.39 & 0.83 & 1.50 & 0.79 & $.10^{*}$ & .14 \\
\hline
\end{tabular}

indicators were cut by half in the whole model, significantly reducing the model size and increasing the power of the analyses.

Measurement invariance was tested as the first step. The data being analyzed cover five separate measurement occasions, each approximately 1 year apart, with responses at each occasion from both husbands and wives. Measurement invariance was assessed in order to determine (1) if there was invariance between husbands' and wives' reports of relational aggression and marital quality, and (2) whether there was invariance across the five measurement occasions for these measures. Invariance was assessed in terms of changes in model fit due to placing equality constraints on the factor loadings across occasions and between partners. The change in comparative fit index (CFI) was used to determine whether the model fit had changed significantly (e.g., $\Delta \mathrm{CFI}>.01$ indicates significant change in model fit; see Little, 2013). The marital quality factor loadings were found to be invariant across both occasions and partners based on the change in CFI criterion $(\Delta \mathrm{CFI}=.004)$. Factor loadings for relational aggression were also found to be invariant $(\Delta \mathrm{CFI}=.005)$, across occasions and partners. Subsequent analysis imposed equality constraints on the factor loadings across occasions and partners for both marital quality and relational aggression when estimating the structural portion of the model, so that the model size was significantly reduced.

Tests of stability of the constructs and cross-lagged effects were tested as the second step. The cross-lag regression paths between husbands' and wives' marital quality and husbands' and wives' relational aggression were analyzed (see Figure 1). Several control variables (education, ethnicity, number of children, age, and marriage length) were analyzed as covariates on both relational aggression and marital quality at each wave of data. The invariance of cross-lag effects and autoregressive coefficient (stability) were examined by comparing a constrained model to an unconstrained model using chi-square difference tests. The chi-square difference between the two models was not significant, indicating that the two models did not differ by constraining the paths and the constrained model would be preferred for parsimony. These tests suggested that the autoregressive paths could be constrained to be equal over time. Overall, the final model fit was adequate, $\chi^{2}(N=4214)=$ $7517.28, p<.001$, root-mean-error of approximation $(\mathrm{RMSEA})=$ $.049, \mathrm{CFI}=.903$. In the following sections, the results are interpreted individually for different portions of the model, although the model was run in its entirety.

Stability paths. First, the autoregressive cross-lag model allowed us to test the stability of the latent constructs over time. Martial quality for both husbands and wives were moderately stable over time (coefficients ranging between $\beta=.51, p<.001$, and $\beta=.57, p<.001$ ). Both types of relational aggression were even more stable over time for both husbands and wives (ranging between $\beta=.71, p<.001$, and $\beta=.86, p<.001)$. See Figures 2 and 3 for full results.

Love withdrawal and marital quality. For husbands' marital quality, love withdrawal by both husbands (all comparisons $p<$ .05 ) and wives (all comparisons $p<.001$ ) were associated with lower levels of marital quality over time (see Figure 2) and the effect was stronger for husband's use of aggression compared to their wives' use ( $\left.\chi_{\text {dif }}^{2}=63.88, d f_{\text {dif }}=1, p<.05\right)$. Conversely, husbands' marital quality was associated with their own engagement in love withdrawal over time (all comparisons $p<.05$ ). Thus, the more either partner uses love withdrawal, the more frequently husbands perceive their marriage to be of lower quality over time. Moreover, the worse the perception of husbands regarding marital quality, the more likely it is that husbands will engage in love withdrawal toward their wives over time.

Additionally, love withdrawal by husbands (all comparisons $p<.001$ ), but not wives, was negatively associated with marital quality as perceived by wives (see Figure 2$)\left(\chi_{\text {dif }}^{2}=52.44, d f_{\text {dif }}=\right.$ $1, p<.05)$. However, marriage quality as perceived by wives did 


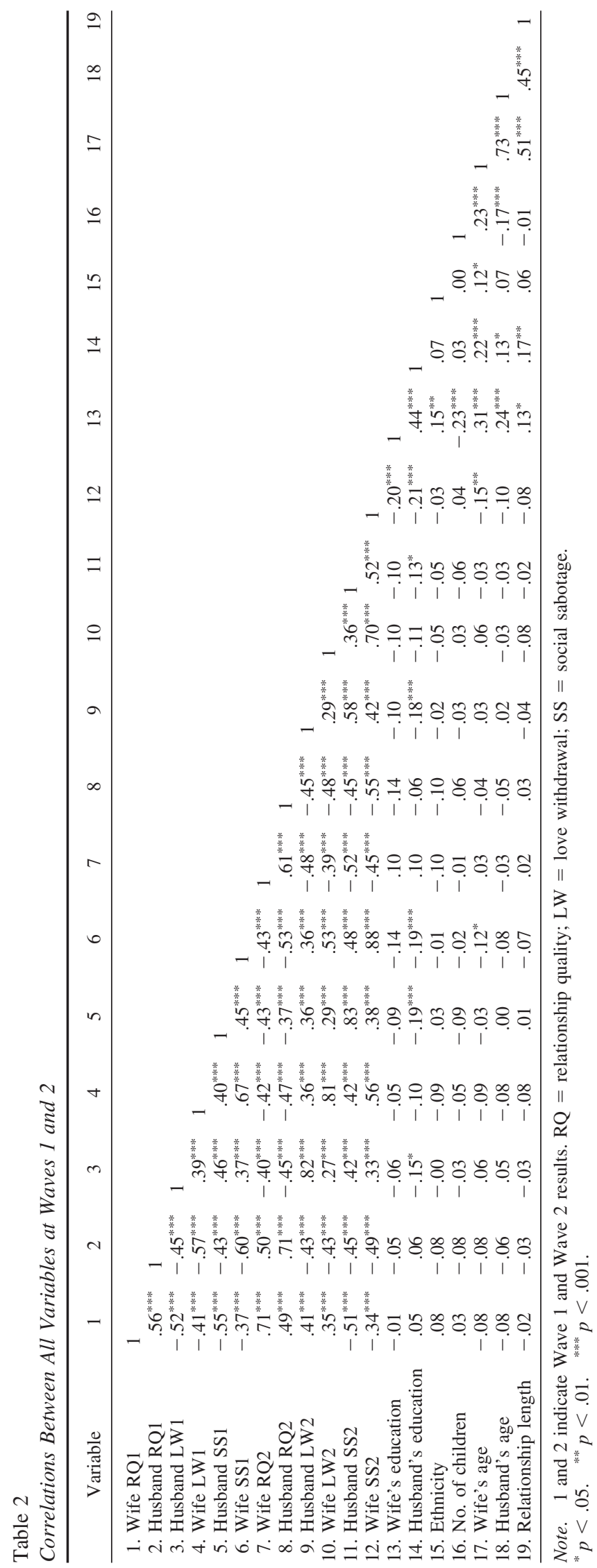

not predict engagement in love withdrawal by either partner over time. These results indicate that, for wives, love withdrawal by husbands is the pivotal influence for wives' perceptions of marital quality.

Social sabotage and marital quality. For husbands, there was a bidirectional effect of husbands' social sabotage and their own perceptions of marital quality over time (see Figure 3). First, husbands' use of social sabotage had an effect on perceived marital quality over time, even when controlling for earlier relationship quality and the other control variables (all comparisons $p<.01$ ). In contrast, wives' use of social sabotage did not have any effect on husbands' perceptions of marital quality over time (or vice versa) $\left(\chi_{\text {dif }}^{2}=285.29, d f_{\text {dif }}=1, p<.05\right)$. However, relationship quality as perceived by the husband also had an effect on social sabotage over time (all comparisons $p<.001$ ).

This same pattern was not found for wives' perceptions of marital quality (see Figure 3). Their use of social sabotage had no connection to their own perceptions of marital quality (all comparisons $p>.05$ ), but husbands' use of social sabotage did predict lower levels of wives' marital quality over time $\left(\chi_{\text {dif }}^{2}=38.71\right.$, $\left.d f_{\text {dif }}=1, p<.05\right)$. Wives' relationship quality had no connection to their own use of social sabotage over time. Thus, engagement of husbands in social sabotage explained their wives' feelings of marital quality over time.

\section{Growth Curve Modeling}

A growth curve model allowed us to examine how the constructs changed over time and how the changes were associated with one another. Like standardized random variables, the latent constructs were specified to have means of zero and unit variance at the first measurement. The growth model was first estimated without any covariates and found to fit the data well $\left(\chi_{[3756}^{2}\right]=$ 5751.64, $p<.001$; CFI $=.93$; RMSEA $=.04)$. Curve change patterns were checked against the linear ones in terms of model comparisons. Wives' perceived marital quality was found to decrease in a nonlinear pattern with a mean of $-.24(p<.01)$ for the linear factor and a mean of $.03(p<.01)$ for the quadratic factor. The variances for these slope factors were not significantly different from zero. The husbands' perceived marital quality was also found to decrease but in a linear trend with a mean of $-.12(p<$ $.01)$ for the slope factor and a small variance $.02(p<.01)$. In addition, husbands' love withdrawal also decreased slightly with a linear trend, with a mean of -.03 and a small variance $.02(p<$ $.01)$.

A second growth model with the covariates were estimated and correlations of the slope factors after controlling for the covariates effects are listed in Table 3. The estimates in the table suggest that changes in marital quality of wives and husbands were correlated with each other. In addition, changes in love withdrawal and social sabotage were negatively correlated with change in marital quality. Namely, increases in the love withdrawal and social sabotage were associated with decrease in marital quality over a 5-year period. Chi-square differences tests indicated that the correlations between wives' change in relational aggression (love withdrawal and social sabotage) and husbands' marital quality were significantly different from husbands' change in relational aggression (love withdrawal and social sabotage $)$ and wives' marital quality $\left(\chi_{\text {dif }}^{2}=\right.$ $5.81, d f_{\text {dif }}=1, p<.05$, and $\left.\chi_{\text {dif }}^{2}=4.00, d f_{\text {dif }}=1, p<.05\right)$. 


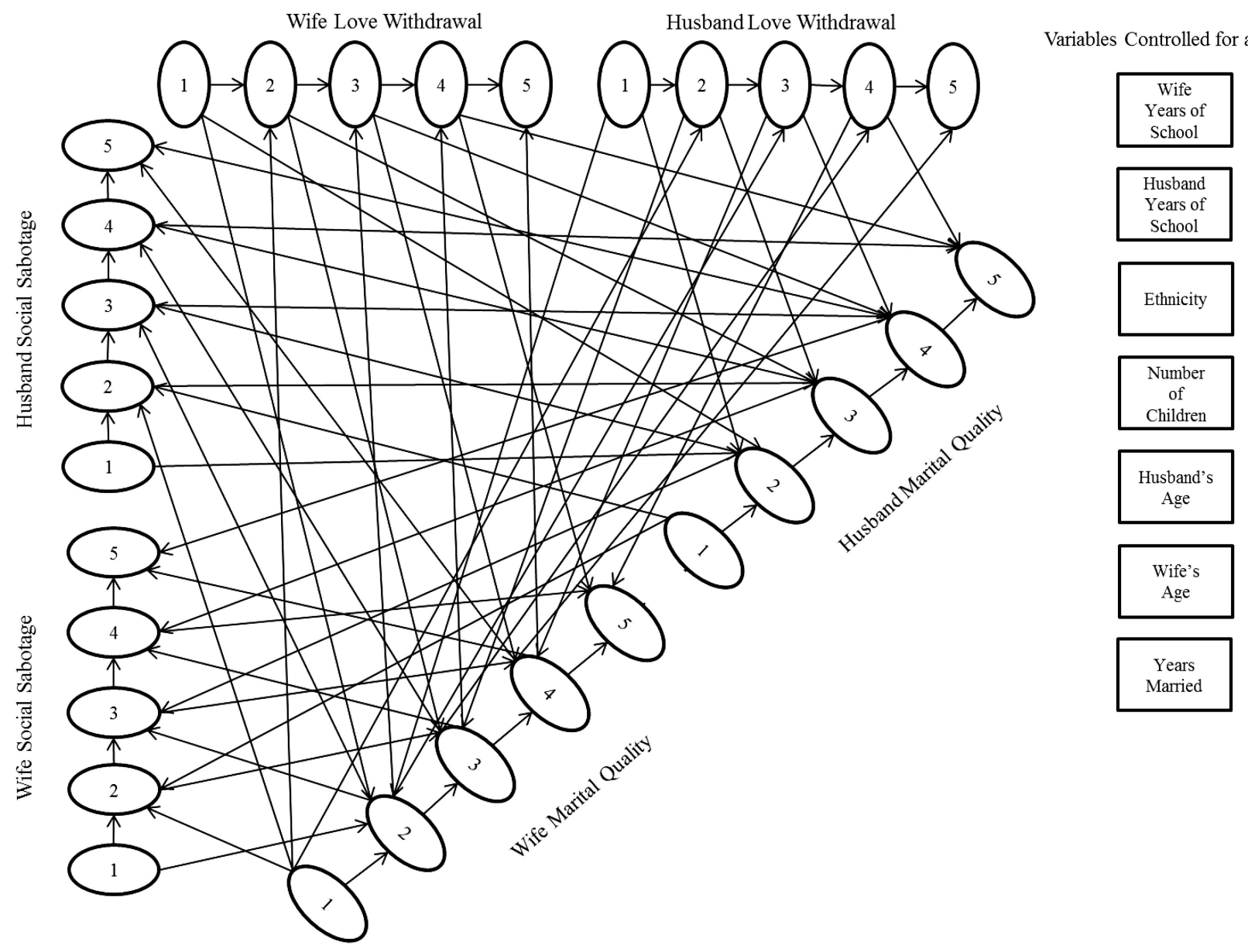

Figure 1. Autoregressive cross-lag panel model between husbands' and wives' marital quality and relational aggression subscales.

\section{Discussion}

The current study examined associations between relational aggression and relationship quality over time. As a reminder to the reader, we measured spousal perceptions of relational aggression (love withdrawal and social sabotage) as opposed to self-reports of the behavior. For readability, we refer to these behaviors as actual aggression as opposed to "wives' perceptions of husband's relational aggression." However, the reader should keep this distinction in mind when interpreting the results as perceptions of behavior may be different from actual behavior.

On the whole, wives used both love withdrawal and social sabotage at higher levels than their husbands, though effects were small to moderate in size. This finding was consistent across a 5 -year period of time. Additionally, social sabotage was much less common than love withdrawal at each time period. Social sabotage represents an extreme form of relational aggression, where one spouse is actively turning to others outside the relationship to manipulate and damage the other spouse's reputation and existing relationships. Love withdrawal was more common and may represent a less extreme form of aggressive behavior. Carroll and colleagues (2010) have suggested that because social sabotage involves people outside of the marriage there is great potential for these behaviors to do lasting damage to the marital relationship. This type of aggressive behavior may seem like more of a betrayal because one partner is discussing personal details about the relationship outside the boundaries of the marriage. With love withdrawal, only the two partners are typically involved and whatever harm is inflicted may be more easily reversed.

Future longitudinal research could examine the development of these two forms of subtypes of aggression over time. It may be that couples use of both subtypes of relational aggression appear simultaneously. It is also possible that the appearance of relational aggression may be more developmental in nature. Couples may begin to use love withdrawal when things are not going well in the relationship. However, if that strategy does not "work" in fixing the relationship, spouses may turn to using social sabotage to harm each other. This would be similar to research on other forms of couple conflict behavior that have found a "process cascade" where behaviors progress from less harmful to more harmful patterns over time (Gottman, 1994). Future research is needed to more fully delineate the developmental pathways of different subtypes of relational aggression to see if a similar process cascade occurs moving from love withdrawal to social sabotage behaviors. 


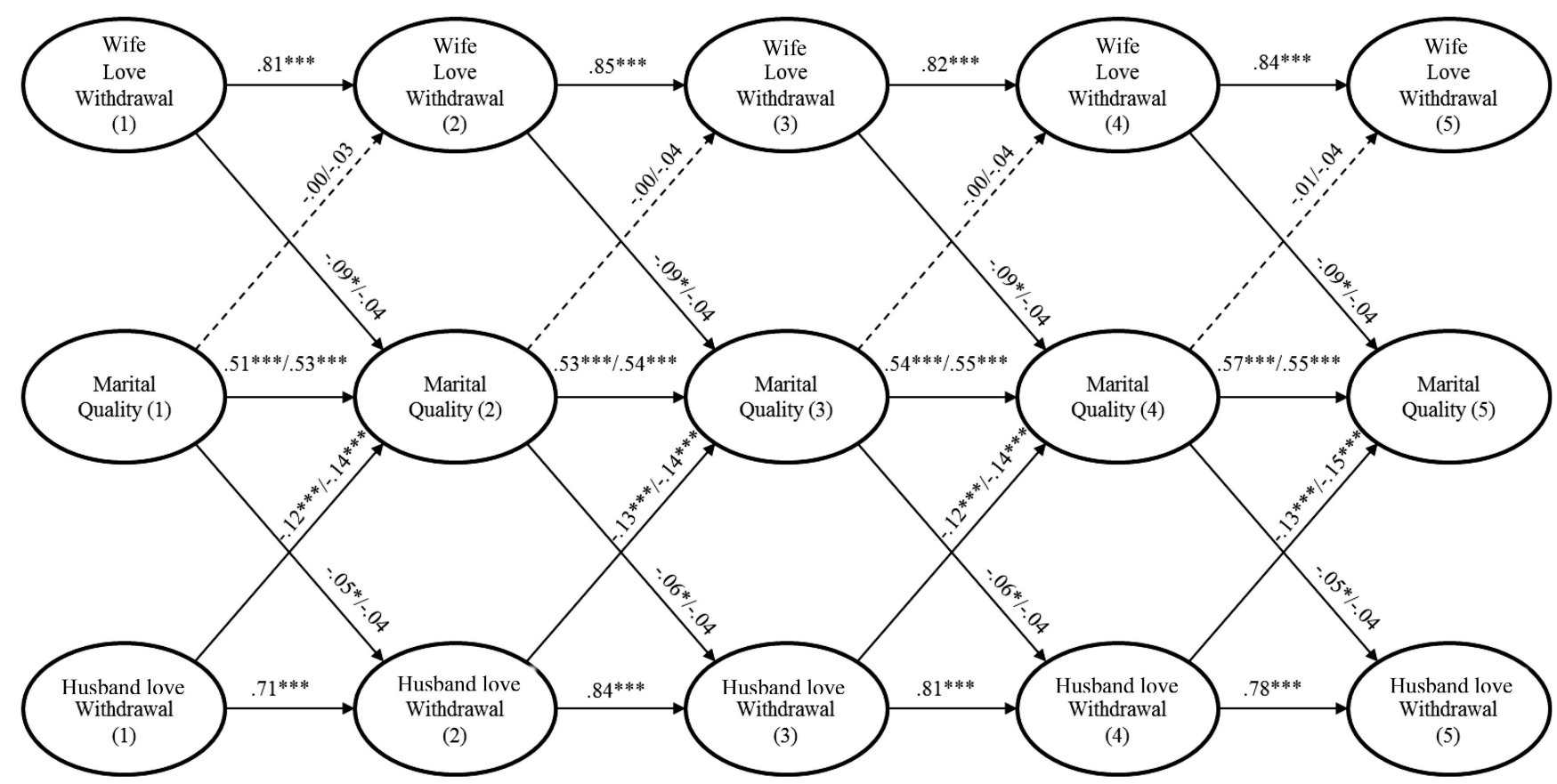

Variables Controlled for at each wave
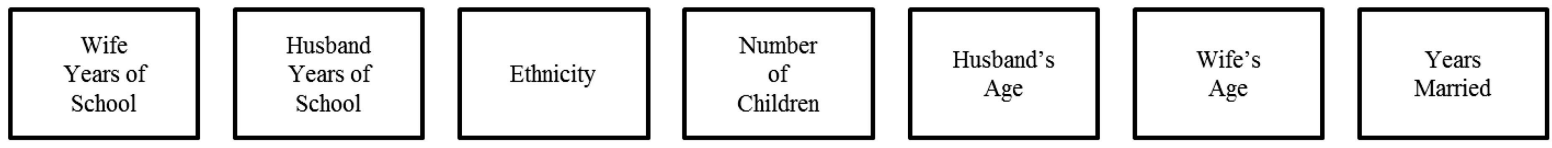

Figure 2. Autoregressive cross-lag panel model, only displaying husband and wife love withdrawal and marital quality. All reported coefficients are standardized; solid lines denote statistically significant paths (for husbands, wives, or both). Husbands' coefficients are before the shill, wives' are after the shill. Marital quality for husbands and wives were modeled separately in the analyses, but are combined here for readability. Marital quality for husbands is shown before the shill. Marital quality for wives is shown after the shill. ${ }^{*} p<.05 .{ }^{* * * *} p<.001$.

Growth curve analyses suggested that romantic relational aggression and marital quality are related over a 5-year period. Specifically, as love withdrawal and social sabotage increased over time, marital quality decreased for both men and women. Or in other words, if couples can decrease their use of relationally aggressive strategies, then martial quality tends to increase. These results suggest that relational aggression in marriage and marital quality are related over time (at least over a 5-year period). To examine direction of effects, we tested a cross-lagged model examining these relationships on a year-to-year basis across 5 years of marriage. Both love withdrawal and social sabotage were associated with marital quality for both husbands and wives over time. However, associations depended on the sex of the perpetrator and perceived quality of the relationship. When husbands use love withdrawal, they themselves view their marriage as lower quality over time. The use of love withdrawal does not appear to be a relationship-enhancing technique, and may potentially hurt the relationship over time. Husbands' love withdrawal was also associated with wives' perceptions of the quality of their marriage over time; perhaps because women tend to be more observant of poor communication patterns and may become hurt by his distancing himself from her (Eldridge \& Christensen, 2002). We also found that as wives use more love withdrawal, husbands perceive their marriage as lower quality over time, although wives themselves do not view their marriage as lower quality.

Wives' use of love withdrawal may be a resource used to gain more power in the marriage and draw attention to desired change within the relationship (Molm, 1990). Love may be partially perceived as a source of physical intimacy by husbands and emotional intimacy by wives (Sumter, Valkenburg, \& Peter, 2013). As wives use more love withdrawal, husbands may see this as withdrawing sex which may negatively impact their perception of the relationship. When husbands use more love withdrawal, wives may not have their emotional intimacy needs fulfilled, which may influence their perception of their marital quality. Relational aggression, including ignoring and giving the silent treatment, is more common than physical aggression among female relationships (Crick \& Grotpeter, 1995). When a wife withdraws love from her husband, she may not see the negative effects because these relationally aggressive behaviors are more commonplace and perhaps even accepted in many of her female relationships. Thus, a wife's use of love withdrawal may not affect her perception of their relationship quality, and is seen paradoxically as a form of pursuit of change rather than true withdrawal. 


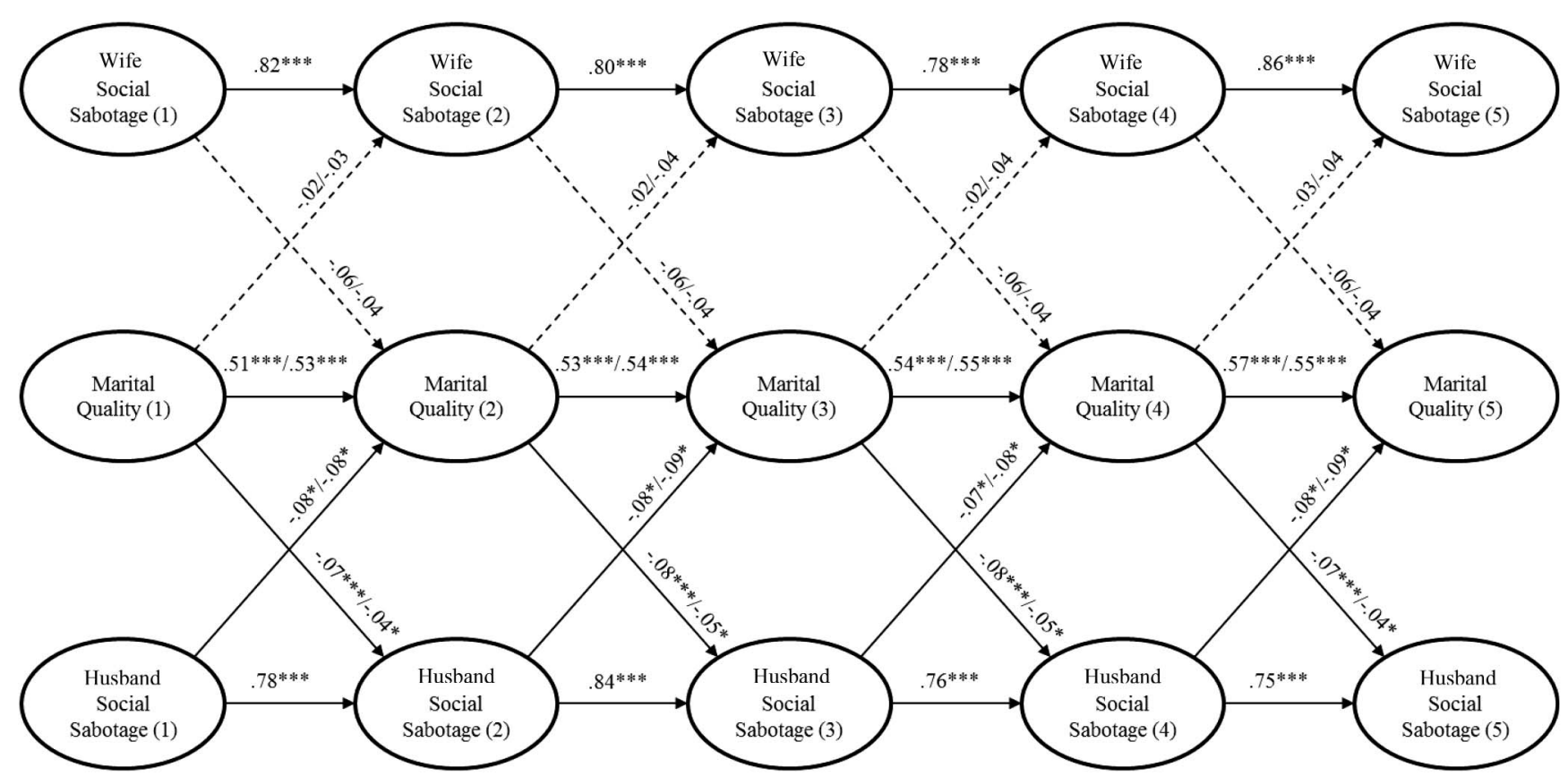

Variables Controlled for at each wave
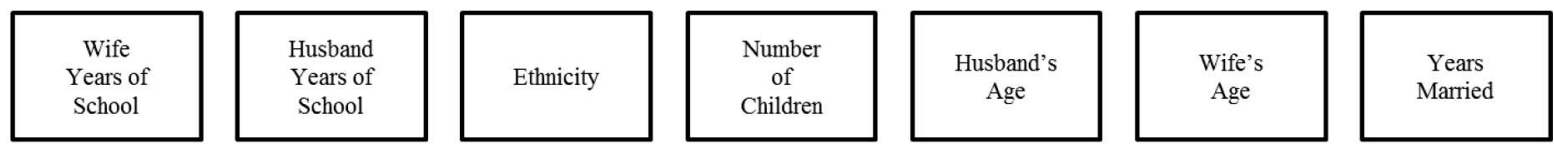

Figure 3. Autoregressive cross-lag panel model, displaying only husband and wife social sabotage and marital quality. All reported coefficients are standardized; solid lines denote statistically significant paths (for husbands, wives, or both). Marital quality for husbands and wives were modeled separately in the analyses, but are combined here for readability. Marital quality for husbands is shown before the shill. Marital quality for wives is shown after the shill. ${ }^{*} p<.05 .{ }^{* * * *} p<.001$.

Conversely, wives' use of social sabotage had no effect on her relationship quality or on her husband's perceived relationship quality. Again, this suggests that such behaviors may be seen as more gender-appropriate behavior aimed at soliciting relationships, rather than as indicators of relationship distress. However, a husband's use of social sabotage was associated with lower levels of relationship quality of his wife. This pattern may be perceived as less socially normative for men and more a reflection of real relationship dissatisfaction. Plus, if men are perceived as having more power in the relationship, such behaviors may be seen as more threatening to the continuance of the relationship. The severity of social sabotage as a conflict behavior in marriage was confirmed in the 5-year period examined in the current study. Since social sabotage involves other individuals, it can be very damaging to the relationship (Carroll et al., 2010). However, the quality of the relationship predicted future social sabotage for husbands, but not for wives. When one spouse feels unhappy with the relationship, he or she may turn to using manipulative and coercive strategies for a number of reasons, including trying to teach the other spouse "a lesson," cries for attention, or attempts to

Table 3

Correlation Estimates of Slope Factors From a Growth Model With Covariates

\begin{tabular}{lccccc}
\hline \multicolumn{1}{c}{ Factor } & $\begin{array}{c}\text { Wives' } \\
\text { marital } \\
\text { quality }\end{array}$ & $\begin{array}{c}\text { Husbands' } \\
\text { marital } \\
\text { quality }\end{array}$ & $\begin{array}{c}\text { Wives' } \\
\text { love } \\
\text { withdrawal }\end{array}$ & $\begin{array}{c}\text { Husbands' } \\
\text { love } \\
\text { withdrawal }\end{array}$ & $\begin{array}{c}\text { Wives' } \\
\text { social } \\
\text { sabotage }\end{array}$ \\
\hline Husbands' marital quality & $.89^{*}$ & & & & \\
Wives' love withdrawal & $-.91^{*}$ & $-.96^{*}$ & & \\
Husbands' love withdrawal & $-.54^{*}$ & $-.92^{*}$ & $.70^{*}$ & \\
Wives' social sabotage & $-.64^{*}$ & $-.67^{*}$ & $.74^{*}$ & .37 & $.45^{*}$ \\
Husbands' social sabotage & $-.61^{*}$ & $-.84^{*}$ & $.77^{*}$ & $.95^{*}$ \\
\hline
\end{tabular}

${ }^{*} p<.01$. 
simply hurt, demean, or ruin other's relationship. If these behaviors are engaged in with the intent of soliciting change in the relationship, our analyses reveal that these strategies have paradoxical results. They do not improve the relationship over time and are likely to be associated with even worse marital quality in the future. Accordingly, the relationship between social sabotage and relationship quality may be cyclical, and individuals may be caught in a downward spiral of pursuit and withdrawal that may be quelled only when the social sabotage is discontinued.

Notably, these bidirectional relationships applied only to husbands' use of social sabotage. Indeed, social sabotage by wives was not related to marital quality in the cross-lagged models. Accordingly, it appears that husbands' social sabotage may be particularly damaging and toxic in the relationship. Women tend to put greater value on social relationships; thus, it may be that social sabotage by a man is more toxic because a woman may be more likely to notice and feel the negative effects of relational aggression, at least in a marital context (Oka et al., 2016). Furthermore, a wife who is only on the receiving end of relational aggression within the marriage may be especially upset by her husbands' use of such behavior. Finally, men married to women who are avid practitioners of relational aggression may learn how to "fire back" with relational aggression, which may prove particularly surprising and jarring to their partner.

Though a man's use of social sabotage appears to be particularly toxic in a relationship, this does not mean that a woman's use of social sabotage does not matter. Indeed, it is worth highlighting that at the bivariate level and in the growth curve, wives' use of social sabotage is strongly related to marital quality. However, social sabotage by husbands and wives is also strongly correlated; accordingly, it may be that husbands' use of aggression took up most of the variance in the overall model, leaving little unique predictive ability for wives' aggression. This may suggest that not only can spouses personally cascade in their use of relationally aggressive behaviors, but that they likely cascade in unison and use such strategies both proactively and reactively to solicit change or respond to emotional injury.

In general, it may be best that spouses communicate with each other, as opposed to turning to friends or family, when they are unhappy in their relationship. The ability to communicate and address potential problems is very important for the health of a relationship. Getting others involved in marital problems likely does very little to fix the relationship; instead, it may sow the seeds for feelings of hurt and distrust. Such patterns may also create a toxic environment around the relationship that in time starts to emphasize the couple's struggles, rather than a supportive environment that reflects their strengths. Future research should directly test this hypothesis by addressing whether couples who directly communicate about their problems fare better, individually and as a couple, in comparison with couples who talk with friends. The extent of detail shared with third parties is likely to be an important moderator of any problematic outcomes, as well. Couples who struggle to communicate about problems can also turn to professionals for assistance, thereby obtaining the support of a third party without jeopardizing the privacy of the relationship.

Professionals may also need to help couples understand and modify power dynamics within their relationship. Oka and colleagues (2016) have proposed that addressing power imbalances between spouses may be essential to eliminating relational aggres- sion strategies that have entered into a relationship. In particular, they suggest that Knudson-Martin's (2013) model of couple equality may be helpful to professionals addressing power processes in couple therapy. This model includes four conditions necessary to foster mutual support: shared relationship responsibility, mutual vulnerability, mutual attunement, and mutual influence. According to Oka and colleagues (2016), assessing shared relationship responsibility includes asking questions regarding who does what in the relationship, while addressing mutual vulnerability and attunement requires creating a space safe enough for partners to be able to admit their own weaknesses in front of one another and increasing partners' awareness of one another's needs and feelings. Furthermore, they suggest that fostering mutual influence "includes helping partners learn to accommodate for the sake of the relationship by allowing themselves to be changed and influenced by one another," as well as taking "accountability for mistakes in the relationship, such as relational aggression" (Oka et al., 2016, p. 33). Such an approach may be valuable when relational aggression is conflict driven; however, this approach should not be taken when one partner is controlling and abusive of another person who should not be expected to assume shared responsibility.

There is a key issue that deserves further research scrutiny. This is in regard to how love withdrawal and social sabotage may alternately be considered as either forms of aggression or conflict behaviors. We noted earlier that use of these strategies may serve some instrumental purpose, consistent with conflict strategies, in trying to cope with a difficult situation or pushing the spouse to change their position or otherwise take action to repair the relationship. Aggression is generally defined as behavior enacted with malicious intent, with the intent to either retaliate or manipulate (Crick \& Grotpeter, 1995). In this study, a few of the social sabotage items seem to clearly signal contempt (e.g., "My partner has tried to damage my reputation ..."; "My partner tries to embarrass me ...") but it is not entirely clear. In particular, do some partners engage in what appears to be malicious behavior when they actually seek to push for change in the relationship? Beyond this, does it matter if social sabotage is intended as a conflict strategy when the partner actually perceives it as malicious? To truly understand what is happening, we would likely need to compare how the perpetrator and victim perceive the intent behind these strategies. It is possible that couples may agree that relational aggression is a conflict strategy (and should not be taken so seriously) or disagree (e.g., the perpetrator sees it as a conflict strategy while the victim perceives it as malicious). In these two cases, the consequences of relational aggression may be quite different. It may also be that the perception of the victim (the focus of our measurement approach) is the most important for marital quality and stability, regardless of the intent of the perpetrator. Finally, perceptions of the normativity of romantic relational aggression may have a lot to do with the consequences of such behavior, given that normativity suggests acceptability, to a degree.

Though the study had a number of strengths, including a relatively large sample of couples, both partner- and self-reports, a high retention rate, and multiple waves of data, the study also had a number of notable limitations. First, participants generally came from well-educated, moderately wealthy families and were not very ethnically diverse. Accordingly, these results should be replicated in more diverse samples. Additionally, most couples had 
been in their existing relationship for a number of years and were in their mid-40s at the first wave of data collection. At this point, many marriages are relatively stable, and couples have already experienced a host of problems that they have overcome together. Future research could examine relational aggression at different stages of relationships. It may be that particularly high levels of relational aggression may end some relationships early on.

There is also a potential limitation in relying upon spouse reports of social sabotage. Since social sabotage is likely to frequently happen behind the spouse's back, we may be substantially underestimating the true prevalence of such behaviors. Spouse reports affirm the presence of social sabotage only if the spouse is actually aware of it. Future research should consider self-reports of social sabotage as a point of contrast. Of course, self-reports may be hampered by reporting problems as well. A spouse who believes that corumination is a natural part of social interaction with friends and family may underreport it as an aggressive strategy.

We also only examine relational aggression as a predictor of marital quality over time. Though we found a number of prospective relationships between these two variables, it is possible that some other chronic relationship transgression (e.g., repeated infidelity, gambling) may account for both relational aggression and lower marital quality across the course of time for a marital relationship. We hope that future research examines relational aggression in a host of other relationship behaviors. It is also possible that our conceptualization of relational aggression has not fully addressed the complete range of such behaviors that may be inflicted, particularly by men. Future research may consider through qualitative methods how couples describe the mix of relationally aggressive strategies present in their relationships. Finally, the current study examined relational aggression in married couples only. Relational aggression may function differently in cohabiting or dating couples, and future research could compare long-term associations with martial quality in these samples.

By definition, relational aggression attempts to harm the relationship. The current study is the first of its kind to show that romantic relational aggression may be damaging over time in a marital context. We should note that both love withdrawal and social sabotage were extremely stable across a 5-year period. It appears that couples enter into a pattern of using different forms of relational aggression that is difficult to escape. Accordingly, family therapists may wish to examine the overall pattern of different forms of relational aggression in any given relationship. It may be that some couples need professional help to break the cycle of relational aggression and poor relationship quality. Therapists are encouraged to discuss both love withdrawal and social sabotage over time, as these strategies tend to have slightly different predictive ability in the long term. We encourage couples everywhere to avoid using relational aggression in their romantic relationships. A famous children's nursery rhyme says, "Sticks and stones may break my bones, but words will never hurt me." The current study shows that not only words, but the withdrawal of words, affection, and attention, can be painful and may even damage the relationship over time.

\section{References}

Birditt, K. S., Brown, E., Orbuch, T. L., \& McIlvane, J. M. (2010). Marital conflict behaviors and implications for divorce over 16 years. Journal of
Marriage and Family, 72, 1188-1204. http://dx.doi.org/10.1111/j.17413737.2010.00758.x

Carroll, J. S., Nelson, D. A., Yorgason, J. B., Harper, J. M., Ashton, R. H., \& Jensen, A. C. (2010). Relational aggression in marriage. Aggressive Behavior, 36, 315-329.

Crick, N. R., \& Grotpeter, J. K. (1995). Relational aggression, gender, and social-psychological adjustment. Child Development, 66, 710-722. http://dx.doi.org/10.2307/1131945

Cromwell, R. E., \& Olson, D. H. (Eds.). (1975). Power in families. Beverly Hills, CA: Sage.

Eldridge, K. A., \& Christensen, A. (2002). Demand-withdraw communication during couple conflict: A review and analysis. In P. Noller \& J. A. Feeney (Eds.), Understanding marriage: Developments in the study of couple interaction (pp. 289-322). New York, NY: Cambridge University Press. http://dx.doi.org/10.1017/CBO9780511500077.016

Eldridge, K. A., Sevier, M., Jones, J., Atkins, D. C., \& Christensen, A. (2007). Demand-withdraw communication in severely distressed, moderately distressed, and nondistressed couples: Rigidity and polarity during relationship and personal problem discussions. Journal of Family Psychology, 21, 218-226. http://dx.doi.org/10.1037/0893-3200.21.2 .218

Follingstad, D. R. (2009). The impact of psychological aggression on women's mental health and behavior: The status of the field. Trauma, Violence, \& Abuse, 10, 271-289. http://dx.doi.org/10.1177/1524838009334453

Gallagher, E., Huth-Bocks, A., \& Schmitt, T. (2015). The impact of mothers' relationship quality and parenting on children's peer relationships. Journal of Family Issues, 36, 421-442. http://dx.doi.org/10.1177/ 0192513X13487680

Gottman, J. M. (1994). What predicts divorce? Hillsdale, NJ: Erlbaum.

Graham-Kevan, N., \& Archer, J. (2009). Control tactics and partner violence in heterosexual relationships. Evolution and Human Behavior, 30, 445-452. http://dx.doi.org/10.1016/j.evolhumbehav.2009.06.007

Heavey, C. L., Christensen, A., \& Malamuth, N. M. (1995). The longitudinal impact of demand and withdrawal during marital conflict. Journal of Consulting and Clinical Psychology, 63, 797-801. http://dx.doi.org/ 10.1037/0022-006X.63.5.797

Heavey, C. L., Layne, C., \& Christensen, A. (1993). Gender and conflict structure in marital interaction: A replication and extension. Journal of Consulting and Clinical Psychology, 61, 16-27. http://dx.doi.org/10 $.1037 / 0022-006 X .61 .1 .16$

Holley, S. R., Sturm, V. E., \& Levenson, R. W. (2010). Exploring the basis for gender differences in the demand-withdraw pattern. Journal of Homosexuality, 57, 666-684. http://dx.doi.org/10.1080/00918361003712145

Kluwer, E. S., Heesink, J. A. M., \& Van De Vliert, E. (2000). The division of labor in close relationships: An asymmetrical conflict issue. Personal Relationships, 7, 263-282. http://dx.doi.org/10.1111/j.1475-6811.2000 .tb00016.x

Knudson-Martin, C. (1997). The politics of gender in family therapy. Journal of Marital and Family Therapy, 23, 421-437. http://dx.doi.org/ 10.1111/j.1752-0606.1997.tb01054.x

Knudson-Martin, C. (2013). Why power matters: Creating a foundation of mutual support in couple relationships. Family Process, 52, 5-18. http:// dx.doi.org/10.1111/famp.12011

Lewin, A., Mitchell, S. J., \& Ronzio, C. R. (2013). Developmental differences in parenting behavior: Comparing adolescent, emerging adult, and adult mothers. Merrill-Palmer Quarterly, 59, 23-49. http://dx.doi.org/ 10.1353/mpq.2013.0003

Linder, J. R., Crick, N. R., \& Collins, W. A. (2002). Relational aggression and victimization in young adults' romantic relationships: Associations with perceptions of parent, peer, and romantic relationship quality. Social Development, 11, 69-86. http://dx.doi.org/10.1111/1467-9507 .00187

Little, T. D. (2013). Longitudinal structural equation modeling. New York, NY: Guilford Press. 
Molm, L. D. (1990). Structure, action, and outcomes: The dynamics of power in social exchange. American Sociological Review, 55, 427-447. http://dx.doi.org/10.2307/2095767

Morales, J. R., \& Crick, N. R. (1998). Self-report measure of aggression and victimization. Unpublished manuscript.

Nelson, D. A., \& Carroll, J. S. (2006). Couples Relational Aggression and Victimization Scale (CRAViS). Unpublished manuscript.

Nelson, D. A., \& Coyne, S. M. (2009). Children's intent attributions and feelings of distress: Associations with maternal and paternal parenting practices. Journal of Abnormal Child Psychology, 37, 223-237. http:// dx.doi.org/10.1007/s10802-008-9271-3

Nelson, D. A., Robinson, C. C., \& Hart, C. H. (2005). Relational and physical aggression of preschool-age children: Peer status linkages across informants. Early Education and Development, 16, 115-140. http://dx.doi.org/10.1207/s15566935eed1602_2

Nelson, D. A., Springer, M. M., Nelson, L. J., \& Bean, N. H. (2008). Normative beliefs regarding aggression in emerging adulthood. Social Development, 17, 638-660. http://dx.doi.org/10.1111/j.1467-9507.2007 .00442.x

Norton, R. (1983). Measuring marital quality: A critical look at the dependent variable. Journal of Marriage and the Family, 45, 141-151. http:// dx.doi.org/10.2307/351302

Oka, M., Brown, C. C., \& Miller, R. B. (2016). Attachment and relational aggression: Power as a mediating variable. American Journal of Family Therapy, 44, 24-35. http://dx.doi.org/10.1080/01926187.2015.1105716

Orbuch, T. L., Veroff, J., Hassan, H., \& Horrocks, J. (2002). Who will divorce: A 14-year longitudinal study of Black couples and White couples. Journal of Social and Personal Relationships, 19, 179-202.

Panuzio, J., \& DiLillo, D. (2010). Physical, psychological, and sexual intimate partner aggression among newlywed couples: Longitudinal prediction of marital satisfaction. Journal of Family Violence, 25, 689699. http://dx.doi.org/10.1007/s10896-010-9328-2
Rhoades, G. K., Stanley, S. M., \& Markman, H. J. (2012). The impact of the transition to cohabitation on relationship functioning: Crosssectional and longitudinal findings. Journal of Family Psychology, 26, 348-358. http://dx.doi.org/10.1037/a0028316

Rose, A. J. (2002). Co-rumination in the friendships of girls and boys. Child Development, 73, 1830-1843. http://dx.doi.org/10.1111/14678624.00509

Stappenbeck, C. A., \& Fromme, K. (2014). The effects of alcohol, emotion regulation, and emotional arousal on the dating aggression intentions of men and women. Psychology of Addictive Behaviors, 28, 10-19. http:// dx.doi.org/10.1037/a0032204

Sumter, S. R., Valkenburg, P. M., \& Peter, J. (2013). Perceptions of love across the lifespan: Differences in passion, intimacy, and commitment. International Journal of Behavioral Development, 37, 417-427. http:// dx.doi.org/10.1177/0165025413492486

Vogel, D. L., \& Karney, B. R. (2002). Demands and withdrawal in newlyweds: Elaborating on the social structure hypothesis. Journal of Social and Personal Relationships, 19, 685-701. http://dx.doi.org/10 $.1177 / 0265407502195008$

Vogel, D. L., Murphy, M. J., Werner-Wilson, R. J., Cutrona, C. E., \& Seeman, J. (2007). Sex differences in the use of demand and withdraw behavior in marriage: Examining the social structure hypothesis. Journal of Counseling Psychology, 54, 165-177. http://dx.doi.org/10.1037/00220167.54.2.165

Yang, C., Nay, S., \& Hoyle, R. H. (2010). Three approaches to using lengthy ordinal scales in structural equation models: Parceling, latent scoring, and shortening scales. Applied Psychological Measurement, 34, 122-142. http://dx.doi.org/10.1177/0146621609338592

Received March 17, 2016

Revision received November 2, 2016

Accepted November 6, 2016 